\section{O IMPACTO DO MOVIMENTO RENOVADOR DA EDUCAÇÃO FíSICA NAS IDENTIDADES DOCENTES: UMA LEITURA A PARTIR DA "TEORIA DO RECONHECIMENTO" DE AXEL HONNETH}

\author{
THE IMPACT OF THE RENEWAL MOVEMENT OF PHYSICAL EDUCATION ON \\ TEACHERS' IDENTITY: A VIEW BASED ON AXEL HONNETH'S 'THEORY OF \\ RECOGNITION"
}

\section{EL IMPACTO DEL MOVIMIENTO RENOVADOR DE LA EDUCACION FISICA EN LAS IDENTIDADES DOCENTES: UNA LECTURA A PARTIR DE LA "TEORÍA DEL RECONOCIMIENTO" DE AXEL HONNETH}

\section{Thiago da Silva Machado*, Valter Bracht*}

\begin{abstract}
Palavras chave: Educação Física. Indicação de produção científica. Docentes. Crise de identidade.

Resumo: Estuda o impacto do Movimento Renovador da Educação Física nas identidades docentes dos professores da área que concluíram a formação inicial anteriormente à década de 1990, a partir do exame da hipótese de que a "desnaturalização da Educação Física" promovida por essa produção teria incidido fortemente na identidade dos professores. Realiza, para tanto, uma pesquisa empírica a partir de entrevistas semiestruturadas com 13 professores de EF de diferentes estados e regiões brasileiras. Elege a teoria do reconhecimento social de Honneth (2009) como perspectiva de análise, relacionando o "impacto" a um processo tangenciado por uma espécie de gramática moral, destacando as questões de cunho afetivo-moral. Nas considerações finais, destaca a produção do MREF como responsável por dissonâncias, desestabilizações e rupturas na área, mas, também, a potência desse movimento ao enfatizar a necessidade de se pensar a EF articulada com um projeto mais amplo de escolarização.
\end{abstract}

Keywords:

Physical Education; Scientific publication indicators.

Faculty. Identity crisis.

Palabras clave: Educación Física. Indicación de producción científica. Docentes. Crisis de identidad.

Abstract: This article looks into the impact of the Renewal Movement of Physical Education on the identities of PE teachers who completed their initial training before the 1990s. It examines the hypothesis that "PE denaturalization" caused by such production would have had a great impact on teachers' identity. It conducts empirical research based on semistructured interviews with $13 \mathrm{PE}$ teachers from different Brazilian states and regions. It chooses Honneth's (2009) theory on social recognition as its perspective of analysis, underscoring affective-moral issues. It stresses the aforementioned movement as causing dissonance, destabilization, and rupture in the field, but it also underscores also its power by emphasizing the need to think PE in connection with a broader schooling process.

Resumen: Estudia el impacto del Movimiento Renovador de la Educación Física en las identidades docentes de los profesores del área que concluyeron su formación antes de la década de los 90 partiendo de la hipótesis de que la "desnaturalización de la Educación Física" promovida por esa producción habría incidido de manera poderosa en la identidad de los profesores. Para ello, realiza una investigación empírica a partir de entrevistas semiestructuradas a 13 profesores de EF de diferentes Estados y Regiones brasileñas. Escoge la teoría del reconocimiento social de Honneth (2009) como perspectiva de análisis, relacionando el "impacto" a un proceso tocado por una especie de gramática moral, destacando los asuntos de cuño afectivo-moral. En las consideraciones finales se destaca la producción del MREF como responsable por disonancias, inestabilidades y rupturas en el área, pero también la potencia de ese movimiento al enfatizar la necesidad de pensar la EF articulada a un proyecto más amplio de escolarización. de incongruencia entre finalidades y contenidos de los profesores y mayor relación entre contenidos aplicados y aprendizaje de los alumnos.
*Faculdade Católica Salesiana do Espírito Santo. Vitória, ES, Brasil. E-mail: thiago.m_ef@hotmail.com

**Universidade Federal do Espírito Santo. Vitória, ES, Brasil. E-mail: valter.bracht@pq.cnpq.br

Recebido em: 22-11-2015 Aprovado em: 12-04-2016

(c) (1) (8) Licence 


\section{INTRODUÇÃO}

A década de 1980 foi marcada, no campo da Educação Física Escolar brasileira, pelo surgimento de um conjunto de produções e debates que ficou conhecido, posteriormente, como Movimento Renovador da Educação Física (MREF) (CAPARROZ, 1997). Pode ser entendido como um movimento de caráter "inflexor", dado ter representado um forte e inédito esforço de reordenação dos pressupostos orientadores da Educação Física, como, por exemplo, "colocar em xeque", de maneira mais intensa e sistemática, os paradigmas da aptidão física e esportiva que sustentavam a prática pedagógica nos pátios das escolas. A despeito das diferenças internas ao próprio Movimento, pode-se dizer que, naquilo que concerne ao seu segmento crítico ou "revolucionário", destaca-se o fato de a Educação Física (EF) absorver e participar do debate sobre as teorias críticas da educação que se desenvolvia no campo mais geral da Educação no Brasil. Entre outras questões privilegiadas pelo MREF, estava a tentativa de garantir à EF Escolar o status de disciplina escolar - em contraposição à condição de "mera atividade", descrita no Decreto no 69.450, de 1971 (BRACHT; GONZÁLEZ, 2005).

Em estudos anteriores fizemos a constatação de que, para uma parcela de professores de $E F$, aquelas construções teóricas teriam adquirido status de uma espécie de ameaça às suas identidades e práticas (MACHADO et al., 2010). ${ }^{1}$ Situação essa mais recorrente entre professores de uma geração específica, qual seja, a daqueles que concluíram o curso até 0 início dos anos de 1990 e já estavam nas escolas por ocasião da emergência desse Movimento. Tal situação incidiu diretamente nas posturas adotadas em relação à prática pedagógica. ${ }^{2}$

Um dos elementos constitutivos do MREF foi a incorporação de outros pressupostos balizadores para sua fundamentação (as humanidades), o que permitiu à disciplina 0 "estranhamento" necessário para a revisão de suas práticas. 0 tipo de mudança vislumbrada, inédita até aquele momento, ganhou ares de uma verdadeira crise de identidade, na qual a EF se viu diante de questões que não faziam parte de seu cotidiano. Isto colocou à área e aos seus atores uma série de demandas, afinal, a "desnaturalização da EF", na mesma medida em que propiciava aos docentes dessa disciplina a conquista por maior espaço e a redefinição de sua intervenção e papéis na escola, reclamou-lhes a superação de uma postura, digamos, passiva, neutra ou apolítica naquilo que concerne à sua integração no processo pedagógico escolar.

A despeito da existência de diversos estudos acerca do MREF, pouco se produziu acerca do que aquele momento representou experiencialmente para os docentes da área. ${ }^{4}$ Neste artigo, apresentamos a ideia de que o MREF constituiu-se numa produção que representou um tipo de impacto para os professores de EF. É importante dizer que optamos, intencionalmente, pela utilização do termo impacto, em detrimento de outros que poderiam, à primeira vista, apontar para sentidos semelhantes, como: implicações, efeitos, consequências, entre outros. Ao contrário das palavras citadas, a expressão impacto, da maneira como a empregamos, relaciona-se menos com a noção de produto do que com a de processo. Nesse sentido,

\footnotetext{
1 A esse respeito é importante ressaltar que não se trata de desconsiderar a complexidade que envolve a própria configuração do MREF (que, não livre de contradições, encontrou, seja por parte da academia, seja entre grupos de professores escolares, manifestações tanto de apoio como de resistência). Muito mais, corresponde a destacar aquela que parece ser a concepção hegemônica entre os professores de EF Escolar.

2 Entre os desdobramentos desse processo, estaria a situação de que a EF brasileira se encontra, no atual contexto, em um período entre 0 "não mais" e o "ainda não", onde as práticas escolares da EF apresentariam características de uma intervenção "não mais" nos moldes da EF tradicional, mas que, contudo, "ainda não" teria alcançado o status de uma prática renovada (GONZÁLEZ; FENSTERSEIFER, 2009; REZER, 2007).

3 Desnaturalização aqui é entendida como o processo de afirmação da ideia de que a EF é uma produção cultural e histórica e não uma determinação ou necessidade da natureza, ou seja, sua existência e função não podem ser explicadas pelas "leis naturais". 
quando pensamos na noção de impacto do Movimento Renovador, não podemos ignorar a possibilidade de que este é representado, também, por certa contraposição de expectativas normativas e interesses no que tange àquilo que caberia ao professor de EF na escola. Nessa esteira é que se torna profícua a ideia de identidade docente, ou melhor, de um impacto na identidade docente.

Assim, nosso interesse incidiu exatamente nessa lacuna: seria realmente possível falarmos em um impacto do MREF? De que tipo? Como ele teria ocorrido? A partir da compreensão de sua configuração, como poderíamos interpretar as implicações dele derivadas?

\section{METODOLOGIA}

O estudo foi realizado a partir dos princípios epistemológicos das pesquisas qualitativas das Ciências Sociais e Humanas (FLICK, 2004). O material empírico do estudo foi obtido a partir de entrevistas semiestruturadas, com 13 professores de EF residentes em nove municípios brasileiros, das cinco macrorregiões do Brasil. É importante destacar que a definição do número de colaboradores, bem como o fato de optarmos por abarcar sujeitos de cidades e regiões distintas, não teve intenção quantitativa ou comparativa; muito mais, referiu-se a nossa busca por mapear o fenômeno em variados contextos. ${ }^{5} \mathrm{O}$ critério para a seleção dos colaboradores foi o de que os docentes deveriam já estar em atividade na EF Escolar no período em que o MREF se desencadeou. Foram realizadas duas entrevistas presenciais com cada um dos professores, que foram gravadas em áudio e, posteriormente, transcritas. As interpretações, a partir da análise de conteúdo, foram subsidiadas pela teoria do reconhecimento social do filósofo alemão Axel Honneth (2007; 2009).

A seguir apresentamos o aporte teórico da investigação, com ênfase nas categorias/ conceitos extraídos do referencial honnethiano, imbricado com a noção de identidade, para a qual a obra de Mead (1972) assume grande importância. Na sequência temos as análises e interpretações do material empírico e as considerações finais.

\section{A TEORIA DO RECONHECIMENTO SOCIAL DE AXEL HONNETH E A CONSTRUÇÃO INTERSUBJETIVA DAS IDENTIDADES}

A reformulação da "Teoria Crítica da Sociedade" desenvolvida por Axel Honneth ${ }^{6}$ busca dar centralidade, no cenário atual, às relações intersubjetivas de reconhecimento para a compreensão da dinâmica das relações e conflitos sociais. Nessa direção, o reconhecimento pelos demais membros de uma comunidade é tomado como instrumento fundamental para a autonomia e a autorrealização dos indivíduos, dado o entendimento de que é no reconhecimento social intersubjetivo que os indivíduos e os grupos formam suas identidades.

A atualização sistemática da teoria do reconhecimento realizada por Honneth apoia-se fortemente na Psicologia Social de George Herbert Mead (1972), que, em sua obra clássica Mind, Self and Society, versa sobre o que chama de construção social do Self. Para esse autor, a

\footnotetext{
5 Ainda que as identidades sejam sempre singulares, o material empírico acumulado no estudo permitiu-nos identificar recorrências no que se refere à relação dos colaboradores com aquela produção acadêmica. Assim, apesar dos limites de espaço, os trechos das entrevistas aqui destacados são representativos do tipo de impacto nas identidades evidenciado.

6 Professor da Universidade de Frankfurt, Axel Honneth é considerado um dos principais pensadores alemães da atualidade. Após ter sido assistente de Jürgen Habermas, ocupa, hoje, o cargo de diretor do Instituto de Pesquisa Social.
} 
constituição da consciência de si está diretamente atrelada ao desenvolvimento da consciência de significados possibilitados pela linguagem, pois, ao reagir a si próprio, na percepção do seu gesto vocal, na mesma medida em que o faria um parceiro de interação, o sujeito pode obter sua autoimagem, alcançando, dessa maneira, consciência de sua identidade.

Com essa afirmação, Mead fornece indícios da importância por ele conferida ao processo de socialização como instância determinante do Self. No entanto, o processo de individuação não pode ser desvinculado do processo de socialização. Consoante a isso, Mead (1972, p. 184) nos apresenta um conceito fundamental em sua obra: o "outro generalizado".

A comunidade ou grupo social organizado, que proporciona ao indivíduo sua unidade do 'Self pode ser chamada de 'o outro generalizado'. A atitude do outro generalizado é a atitude de toda a comunidade. Assim, por exemplo, no caso de um grupo social, como o de uma equipe de futebol, a equipe é o outro generalizado, na medida em que intervém - como processo organizado ou atividade social - na experiência de qualquer um de seus membros (tradução nossa).

Para melhor compreender o papel desse outro generalizado, é necessário, antes, tratarmos dos componentes do Self como descritos por Mead. De acordo com o autor, o Self humano é constituído por dois elementos indissociáveis: o "Eu" e o "Me". O "Me" diz respeito à presença do outro na consciência do indivíduo, este deve estar consciente da existência do outro em si. Já o "Eu" se refere à atitude do indivíduo em frente aos atos/ações da comunidade, tal como essa mesma comunidade aparece em sua consciência.

Em linhas gerais, a construção da categoria "outro generalizado" permite a Mead incluir, em sua análise das relações interativas, a questão das normas morais, pois a autoimagem que os sujeitos fazem de si, na perspectiva dos parceiros de interação, deve corresponder não somente a exigências cognitivas do comportamento, mas a expectativas normativas em relação aos demais membros da coletividade. Mead (1972), contudo, ao tratar do potencial criativo do 'Eu', amplia o modelo teórico até então construído. Trata-se de falar de um "Eu" que se comporta como contraparte psíquica do "Me". Essa constatação permite que Mead fale, portanto, de seres (e seus Selves) que se desenvolvem socialmente, mas que têm garantidas suas pretensões de individualidade. Nessa perspectiva, o processo de individuação não deve, em nenhuma medida, ser compreendido como "descolado" das relações sociais existentes (ou seja, os sujeitos são capazes de "reagir" a essa socialização, mas o fazem "de dentro" desse mesmo processo).

Especificamente acerca da teoria do reconhecimento, a tipologia fenomenológica apresentada por Honneth (2009), portanto, aponta que esse reconhecimento (autorrealização) se dá em três diferentes dimensões da vida: desde o âmbito privado (esfera do amor), passando pelas relações jurídicas (esfera do direito), até a estima social (esfera da solidariedade). De modo complementar, apresenta também as formas de denegação do reconhecimento, ou seja, formas de desrespeito decorrentes do não reconhecimento de alguma dessas dimensões de autorrealização. A interpretação apresentada é de que tais padrões de reconhecimento são necessários para a manutenção da integridade do ser humano. Assim, quando esses padrões são violados, a identidade do sujeito é ameaçada,

[...] visto que a auto-imagem normativa de cada ser humano, de seu 'Me', como disse Mead, depende da possibilidade de um resseguro constante no outro, vai de par com a experiência do desrespeito o perigo de uma lesão, capaz de desmoronar a identidade da pessoa inteira (HONNETH, 2009, p. 213-214). 
Ou seja, para cada relação prática de reconhecimento, podem ser percebidas, respectivamente, categorias morais de desrespeito. Para Honneth (2009), as situações de reconhecimento denegado não se configuram apenas como relações de injustiça, mas há, principalmente, uma violação na compreensão que os próprios sujeitos têm de si mesmos. Nesse sentido é que, para cada forma de desrespeito, se vincula a privação de determinadas pretensões de identidade.

\section{IMPACTO DO MOVIMENTO RENOVADOR DA EF NAS IDENTIDADES DOCENTES SOB A ÓTICA DA TEORIA DO RECONHECIMENTO}

Começou com Metodologia da EF Escolar, teve aula inaugural e tal. No primeiro dia de aula... foi para mim 'assim'... porque você se apresenta, naquela roda inicial... Eu disse: 'PA-1, PROFESSORA DE EDUCAÇÃO FÍSICA, TÉCNICA DE GRD!'. Sabe aquela coisa de você se sentir o máximo por dizer aquilo tudo, ali, na frente, para todo aquele público?! Mas, quando acabou a aula, 'eu estava lá embaixo', porque a professora falou tão mal do esporte, tão mal, mas tão mal... Eu me senti horrível. Eu senti que eu não sabia dizer uma palavra daquela... eu estava entendendo pouco do que eles estavam falando... um palavreado com palavras rebuscadas e eu não estava naquele contexto. Tinha muito militante. $\mathrm{Na}$ época, era o pessoal do PT que tava organizando, muita gente que estava fazendo a especialização era da esquerda.

Eu cheguei em casa, fui contar e fiquei pensando: 'Olha, eu trabalhei tantos anos da minha vida assim... tantos anos com o esporte... como é que eu vou negar isso?' E olha que era só para se apresentar, hein?! Só aquela coisa de aula inaugural. Mas eu fui me sentindo horrível, horrível, horrível...

Quando chegou o segundo módulo, eu me apresentei: 'PA-1, PROFESSORA DE EDUCAÇÃO FÍSICA'. Eu não disse mais que eu era técnica de GRD. Por coincidência, a professora que veio para 'dar' o segundo módulo, falou tão mal dessa EF, dessa EF... desse estereótipo... tão ruim! E eu me perguntei: 'O que eu estou fazendo aqui? As duas coisas que eu fiz a minha vida inteira, fui professora de EF e, paralelamente, técnica esportiva... eu construí a minha vida com isso...'. Você entende? Isso tudo foi bom para mim! Muito bom, muito bom! Mas como eu ia explicar isso?... como usar as mesmas palavras deles?

Quando foi o terceiro módulo... eu só disse: 'Sou PA-1'. O pessoal achou graça, mas eu pensava: 'Eu não vou me apresentar mais...' (Entrevista com a professora $P A-1)$.

A passagem que abre esse terceiro tópico corresponde ao relato de uma professora quando do seu primeiro contato mais sistematizado com a produção do Movimento Renovador, em um curso de especialização no ano de 1995. A narrativa dessa docente sintetiza o "conflito" vivenciado por uma parcela dos professores de EF que, muito em função de uma "cultura esportiva", fizeram da identificação entre EF e Esporte o vetor de suas práticas.

A gente via assim: os colegas que mais gostavam do esporte, naquele momento de crítica acirrada, eles se debateram bastante. Até tem um professor lá que diz: 'A gente tem até medo de falar que gosta e ser recriminado', com tanto trauma que a gente veio dessa época, né! Dessa resistência que foi contra o esporte. (Entrevista com a professora PR-2).

O depoimento acima corrobora outros depoimentos mostrando que a ideia de um "impacto de características afetivo-morais" é aquela que talvez melhor represente o que 
percebemos na empiria. Mais do que exemplificar uma situação de desconforto frente à crítica a que foram submetidos, os depoimentos refletem o peso de uma postura legisladora ${ }^{7}$ assumida pelo MREF no processo de construção identitária dos docentes. Ou seja, o relato, aparentemente corriqueiro, de uma professora que "opta" por não mais "afirmar sua identidade", ilustra como o processo vivenciado incidiu na autoimagem positiva que a docente alimentava em outras palavras, em tudo o que para ela correspondia a "ser [boa] professora de EF".

Dizemos isso pois temos pensado na própria área "EF Escolar" como instância responsável pela produção de símbolos, valores e orientações que "devem" ser compartilhados por aqueles que compõem sua coletividade. Ou seja, ao fornecer tais normas de ação, o campo da EF Escolar comporta-se também como o "outro generalizado" da formação das identidades docentes. Afinal, entende Mead (1972), o indivíduo, para fazer parte de uma determinada comunidade (por exemplo, a de professores de EF Escolar), necessita, em certo sentido, "reproduzir" as orientações normativas dessa mesma comunidade.

Isso aí, por exemplo, de onde vem não deixa de balançar a gente, né? Querendo ou não, eles têm muito mais experiências que a gente, né? E quem vai escrever um livro desse tipo, desse 'Metodologia', não vai escrever sem saber nada. Então a gente lê, mas eu li e aproveitei algumas partes, mas algumas partes eu li e continuei no meu caminho, porque é aquele negócio que eu falei com o senhor: na escola, a gente precisa ditar as regras, a gente tem que estar na frente, então, em outras palavras, a gente precisa ganhar, pois, se não ganhar, a gente não sobrevive. (Entrevista com professor GO-1).

Contudo, também as perspectivas normativas colocadas à comunidade docente da EF Escolar se alteram de forma contínua, consequentemente, possibilitam aos professores da área certa revisão das normas de ação adotadas. Se o Movimento Renovador, ao propor uma mudança do paradigma orientador da área, foi responsável por certa "desnaturalização da EF", trata-se de um Movimento que responde, também, pelo estabelecimento de novos padrões normativos para a área, que "deveriam" ser adotados/assumidos nas práticas daqueles que compõem sua coletividade.

Eu acho que muitos tentaram, a maioria tentou. Pelo menos, aqui, na cidade, eu percebo que foi a maioria, ao menos no discurso... Alguns foram se desmotivando e perderam o empenho, cederam... não conseguiram terminar o processo. Mas eu acho que todos tentaram. Quem não tentou foram aqueles que já estavam para se aposentar... que vinham já de um histórico... porque não tem como não respeitar 0 histórico desses professores (Entrevista com professor SP-1).

Reforça isso o fato de que são, exatamente, os discursos acadêmicos que "dão o tom" aos debates/audiências da área e/ou se fazem presentes em diretrizes/documentos orientadores ${ }^{8}$, logo, são também essas discursividades que adquirem o status de mais verdadeiras para 0 campo.

No nosso caso, no Estado, começa a movimentar lá por volta de 1986, com um grupo de professores da rede. Começou um movimento de mexer na educação como um todo, depois, passado esse período, nós tivemos o momento dos Parâmetros Curriculares Nacionais, que eles também trazem, a própria Educação Física vai

7 Dialogando com Bauman (1999; 2010), percebemos que o material empírico produzido aponta a possibilidade de que o MREF seja interpretado como dotado de certo cunho "legislador". Ou seja, particularmente na concepção dos docentes, é como se aquele conjunto de produções e discursos se apresentasse na posição de autoridade capaz de legislar acerca do que passaria a ser legítimo para/na EF. Para maiores informações, indicamos a leitura do capítulo 4 da dissertação de mestrado de Machado (2012).

8 Nas entrevistas realizadas constatamos que os professores, mesmo discordando, sentem-se acuados por não possuírem elementos para "fazer frente" ao ("mais elaborado") discurso acadêmico. 
trazer um enfoque da LDB. Então, mais ou menos, essas coisas começam a ser seguidas, acho que é isso aí... não só o Estado, mas tudo que vinha via MEC, via programa nacional de educação. (Entrevista com professora SC-1).

Tomei consciência desse movimento na época que eu fui ingressar, em 1993, 1994. Teve esse concurso público que falei e a bibliografia realmente tinha todos esses autores, Go Tani, desenvolvimentista, crítico-superadora, tinha o Freire, João Batista Freire e tudo... [...] (Entrevista com professor SP-2).

A questão se complexifica diante de outro aspecto: se parte significativa da produção acadêmica relacionada com a EF Escolar foi, de acordo com as análises de Taborda de Oliveira (2001), produzida sem, contudo, atentar para aquilo que os professores fazem, como fazem e por que fazem (o que corrobora o que chamamos de uma percepção, pelos professores, de uma "postura legisladora" do MREF), deriva-se daí a compreensão de que a parcela que entendeu necessária a transcendência da ordem particular da EF (de seus padrões normativos), no intuito de modificá-la, correspondeu a um número muito reduzido dessa coletividade (docente): a academia. Nessa esteira, a situação observada é a de uma contraposição de expectativas normativas em relação à EF. Quer dizer, a nova EF pela qual "legislavam" os intelectuais da área não encontrou, ao menos num primeiro momento, uma "recepção positiva" na maioria dos casos.

Ah, me veio um sentimento de decepção, de falta de conhecimento. Sabe de, de tudo aquilo que aprendi, há pouco tempo, há 12 anos atrás, na época era pouco tempo, falei, pô? Não valeu nada?! Então tem alguma coisa errada nisso aí. (Entrevista com professor MG-1).

Era pro lado dessa EF crítica, ninguém sabia o que era essa EF crítica. Era aquela coisa de achar que não podia mandar os alunos fazerem mais nada, porque senão seria autoritarismo. Então, foi uma interpretação muito diferente do que realmente era. E os professores da escola, eu quero te dizer, não aceitaram, não. Até porque eles não conseguiram nem ver isso, não vislumbraram nada disso. Isso aparecia em alguns cursos pontuais, vinha um professor e falava, depois outro... mas, não conseguiram ver. (Entrevista com professora PA-1).

Dito de outro modo, se uma parcela de professores que jáatuava em escolas de Educação básica no período em que se "deflagrou" o Movimento Renovador foi formada (socializada na área da EF) a partir de um determinado horizonte de orientações e valores relativamente fixos, o fato de deparar-se com essa crítica, promotora de certa dissolução dos padrões estabelecidos até então, foi justamente gerador de um impacto (dado esse descompasso de "pretensões de EF"). Com base em Mead (1972), podemos dizer que essas reações apresentam um fundo ou uma "gramática moral".

Por sua vez, Honneth (2009, p. 136), ao comentar as coincidências ou pontos de convergência dos escritos de Mead e Hegel, permite-nos ampliar as perspectivas de análise. Para esse autor, da maneira como fora construída sua teoria, a própria proposta de Mead é falar de uma relação de reconhecimento mútuo.

Se o sujeito, pelo fato de aprender a assumir as normas sociais de ação do 'outro generalizado', deve alcançar a identidade de um membro socialmente aceito de sua coletividade, então tem todo o sentido empregar para essa relação intersubjetiva o conceito de 'reconhecimento': na medida em que a criança em desenvolvimento reconhece seus parceiros de interação pela via da interiorização de suas atitudes normativas, ela própria pode saber-se reconhecida como um membro de seu contexto social de cooperação. 
A ampliação de que falamos, portanto, refere-se ao fato de que Honneth (2009), ao fundamentar sua teoria e defender a tese de que as identidades são construídas a partir de relações de reconhecimento social, aponta que essa formação identitária não só é condicionada pelo meio social, mas, em última análise, é carente do assentimento dos parceiros sociais. Nesse sentido, entendemos que os professores de EF, na situação de impacto do MREF, depararam-se com dilemas morais afetos à construção de suas identidades docentes, não apenas por não mais verem reconhecidos seus projetos de EF (por estarem, a partir da nova "ordem" da EF, fora dos padrões normativos "mais legítimos" para a área), mas, principalmente, por "necessitarem" reavaliar/revisar suas crenças em relação ao "ser professor de EF", a fim de encontrar estratégias que lhes permitissem uma afirmação positiva de suas identidades docentes em frente à "comunidade de valores da (renovada) EF".

E pra mim foi difícil isso... porque a gente se sentia culpada por trabalhar o esporte. Agora eu falo com tranquilidade, mas, na época, eu pensava: 'Meu Deus, eu estou trabalhando isso, mas não é pra fazer isso! Isso está errado!' Até entender que a crítica não era ao esporte da forma como ele era 'reproduzido', foi um sofrimento, porque o discurso não chegou desse jeito, chegou, praticamente, como algo que era proibido. Não que fosse proibido, mas, pelas críticas que havia, quem fizesse aquilo era um péssimo professor. 'Ah, aquele professor só trabalha esporte.' Era como se você não desse 'aula de EF' se você só trabalhasse o esporte. (Entrevista com professora ES-1).

Como lembra Winch (2009, p.53), "[...] a formação identitária docente mostra-se vinculada ao sentimento de pertença a um grupo profissional, ao grau de comprometimento do indivíduo com as suas atividades docentes e os valores que ele adota como referência para a sua atuação profissional".

Pensando especificamente no impacto provocado pelo Movimento Renovador, a assertiva destacada auxilia-nos na interpretação de que, principalmente, a crítica ao esporte teria sido responsável por provocar nos docentes o sentimento de desrespeito ou denegação do reconhecimento. Afinal, dada a relação afetiva que com esse conteúdo específico da EF, a postura de crítica radical assumida por aquele discurso renovador apresentou potencial para imprimir naqueles docentes um sentimento de falta de valor próprio, já que significava, também, uma espécie de lesão, por parte dos seus parceiros de interação (a comunidade da EF), das expectativas normativas observadas para afirmação positiva de suas identidades de professor.

Particularmente em relaçãoà “identidade esportiva”, há, também, naliteratura internacional, um exemplo conhecido de crise pessoal vivenciada por um estudante de EF mediante o impacto do contato com a crítica ao esporte. Trata-se do caso destacado por Devís Devís e Sparkes (2001), que narram o episódio de um estudante de EF que, profundamente incomodado com o conteúdo crítico do livro Deporte, cultura y represión, de Partisans (1978), chega ao ponto de queimá-lo. Na compreensão dos autores, o caso em questão revela como o fato de deparar-se com visões distintas das que possuem sobre o mundo ou de suas crenças mais fundamentais pode constituir-se numa experiência vivenciada na forma de uma crise, pois desestabiliza as "narrativas coerentes" que um sujeito [professor] constrói para a sua vida [identidade docente]. 0 exemplo reforça a carga afetiva que envolve a crítica a um fenômeno ou a uma prática com a qual os professores de EF têm tido, historicamente, uma relação muito forte.

Mas, o que eu ficava... era assim... eu me dizia: 'O que foi que eu fiz da minha vida? Ter feito isso tudo que não serve para nada.... Eu me senti uma assassina... me senti uma deseducadora. Talvez, não seja assassina, mas deseducadora. Porque 
eu passei anos da minha vida trabalhando com o esporte e depois vêm me dizer que o que eu fiz foi tudo muito ruim, tudo muito horrivel. (Entrevista com professora PA-1).

Uma das teses de Honneth (2007) é a premissa de que o reconhecimento afetivo atuaria como pressuposto para todo o aprendizado moral. $\mathrm{O}$ autor também postula um "primado do reconhecimento", no qual aponta que o reconhecimento precede o próprio conhecimento. Para Dalbosco (2011), a justificação de tal tese por Honneth corresponde à demonstração de que não é a postura cognitiva, baseada no modelo do observador distante, neutro afetivamente, mas sim a postura de reconhecimento, recheada de afetos e constituída pelo envolvimento direto dos participantes, o modelo que constitui originariamente o laço social. Em síntese, tratase da noção de que é preciso "reconhecer para conhecer".

Nos dizeres de Tavares de Freitas (2010, p. 15):

[...] é fundamental compreender que 0 aprendizado humano de valores morais e normas de conduta depende das relações intersubjetivas que travamos com diferentes parceiros, e que é por meio do reconhecimento deles que passamos a nos conhecer e nos compreender sempre em novos e diferentes âmbitos e, concomitantemente, que é por meio dele que podemos aprender novas formas de pensar, agir e sentir.

A relação entre reconhecimento e conhecimento se nos apresenta produtiva, particularmente, quando tomada como uma "via de mão dupla" em que o reconhecer e 0 conhecer se interpenetram e se condicionam mutuamente. De qualquer forma, a despeito de "reconhecermos" essa ambiguidade, inclinamo-nos a afirmar, com base no exame das falas dos entrevistados, que merece maior atenção, na qualificação da ideia de um impacto do MREF, o fato de que o aspecto afetivo atuou como uma espécie de "filtro" ou "obstáculo" inicial naquela ocasião - daí o seu valor para a compreensão desse processo.

No entanto, ainda que essa "EF renovada" não tenha mobilizado uma parcela dos professores da área, e tampouco a crítica ao esporte tenha encontrado ressonância, já que ambas não adquiriram sentido positivo para eles ("não foram reconhecidas para serem conhecidas"), o fato de não terem sido "seduzidos" por aquela produção não significa que ela não tenha lhes provocado demandas. Pensando na questão da formação identitária, essa situação é melhor explicada quando voltamos nosso olhar para a terceira dimensão do reconhecimento descrita por Honneth (2009), aquela que se refere às relações de solidariedade.

Relacionada com a estima social dos sujeitos, a dimensão da solidariedade é que lhes permite reconhecerem-se positivamente em suas capacidades e propriedades individuais. Ao propiciar uma espécie de "ampliação" da dimensão jurídica (dada a consideração do aspecto afetivo da solidariedade, o que possibilita a valoração social da singularidade), observa-se que, no modo de reconhecimento da estima social, os sujeitos gozam não apenas da possibilidade de referirem-se a si mesmos como moralmente imputáveis (autorrespeito), mas também lhes é permitido que se sintam reconhecidos em suas propriedades concretas individuais.

A noção de "comunidade de valores" assume relevância na consideração dessa dimensão da valoração social. Afinal, é em tal comunidade definida por critérios éticos e formulação de valores que os sujeitos buscam um reconhecimento em conformidade com o valor socialmente definido de suas propriedades concretas individuais que, em certo grau, contribuem para que sejam realizados os objetivos comuns. 
Apropriamo-nos da dimensão do reconhecimento solidário a fim de interpretar a ideia de um não reconhecimento dos "projetos pessoais" dos professores de EF por parte das elaborações do Movimento Renovador, na ocasião em que se buscou uma "reordenação" da área. Quer dizer, tal processo teria sido experimentado por aqueles docentes como uma experiência de um desrespeito no plano da estima social; quadro agravado por aspectos relacionados com a "postura legisladora do MREF" que, até mesmo em função do discurso radical oriundo da assunção de um determinado referencial metateórico por parte daqueles intelectuais, "transparecia" aos professores das escolas a noção de que o único modo legítimo de fazer EF seria algo distinto do que vinham realizando, particularmente diante da ênfase daquele discurso acerca do que a EF não deveria ser.

Se hoje visualizamos esse "Movimento da década de 1980" como responsável por uma espécie de "ampliação da comunidade de valores da EF" - uma interpretação positiva, já que remete à pluralização do horizonte de valores definidos para a área e suas novas possibilidades de práticas e identidades -, em nossa compreensão, trata-se de uma visão possível somente agora, por um olhar em retrospectiva. Afinal, o processo de impacto que vimos analisando, a partir da empiria, revela/aponta que, naquela ocasião, os sentimentos/sensações mais comuns entre os docentes eram os de que se tratava de uma produção que denegava o reconhecimento dos que estavam nas escolas - o que "culminou" na postura de "autodefesa" adotada por muitos.

Entendemos que tais reações resultam, portanto, do conflito vivenciado por muitos professores que, ao "descobrirem" seus projetos não reconhecidos e não legitimados "pela área", tiveram a percepção de que eram dotados de menor valor na coletividade da EF, como denota o trecho de entrevista: "Imagina se um professor da escola vai dizer para um professor da Universidade: 'Eu discordo de ti'. Pesa muito, porque eu acho que professor da escola se sente menor..." (Entrevista com professora RJ-1).

Nessa direção, interpretamos que o MREF, ao ser interpretado por uma parcela dos docentes no sentido de algo que degradava valorativamente os seus padrões de autorrealização, foi vivenciado por esses mesmos docentes exatamente como um desrespeito concernente às relações de solidariedade, uma vez que o sentimento gerado implicava a impossibilidade de aqueles sujeitos se referirem ao modo de condução de suas práticas pedagógicas como uma postura a qual caberia um significado positivo no interior da "comunidade de valores" da EF. Aí residiria, portanto, mais um elemento que nos auxilia na compreensão do impacto do Movimento Renovador nas identidades docentes, pois parte dos professores sentiram-se arrebatados por uma experiência de "[...] falta do próprio valor, porque seus parceiros de interação ferem normas cuja observância o fez valer como a pessoa que ele deseja ser conforme seus ideais de ego [...]" (HONNETH, 2009, p. 223).

\section{CONSIDERAÇÕES FINAIS}

Em nossa investigação procuramos compreender o processo configurado pelo contato dos professores de EF com a literatura renovadora da EF, exercício que, em última análise, nos oferece elementos também para uma maior compreensão da própria situação de indefinição da área em relação à sua prática pedagógica, não ignorando, é claro, outros aspectos que permeiam esse "hiato", como a própria dificuldade de legitimação da EF.

Em síntese, nossa interpretação é de que esse Movimento apresentou como pano de fundo uma espécie de "gramática moral" (ou afetivo-moral). Tal gramática nos permite 
compreender o peso dessa produção não somente como resultado de uma "experiência cognitiva mal-sucedida" - como se a "culpa" fosse dos professores que não compreenderam bem o que estava sendo proposto, e daí o não sucesso da empreitada - mas, também, como consequência da contraposição (ou do impacto!) de expectativas normativas alimentadas para a $E F$, tendo sido fator determinante a relação afetiva dos docentes com o esporte.

Considerando a ideia de que autonomia e reconhecimento são dois conceitos que se sustentam mutuamente e que um não faz sentido sem o outro (FLICKINGER, 2011), pensar na conquista, por parte dos professores, de uma "autonomia docente" configurada pelo pleno desenvolvimento de suas identidades (autorrealização) implica, portanto, atentar também para o reconhecimento afetivo desses indivíduos, dado seu caráter elementar. Sob essa ótica, tratase de falar em uma percepção/aceitação dos sujeitos [nesse caso, o professor, seus projetos, sua identidade] como algo que extrapola em muito a mais cognitiva esfera "jurídico-moral".

Afinal um indivíduo [caberia dizer um professor] pode ter acesso a seus direitos formais e ser 'invisível' emocionalmente para seus pares. Essa ofensa afetiva não é prevista em nenhum código, mas o sofrimento decorrente pode ser muito maior que as ofensas 'materiais' constantes das leis (MATTOS, 2008, p. 61).

Antes de finalizar, convém dizer que tratar o tema do MREF não é tarefa fácil, afinal, além de sua complexidade, trata-se de um tema caro à EF. Esforçamo-nos em não assumir posturas de idolatria ou condenação desse Movimento acadêmico. Da mesma forma, a crítica empreendida não deve ser interpretada como a de "um juiz anacrônico" que não considera as limitações dos atores - sejam intelectuais, sejam professores da escola - no tempo vivido historicamente. Considerando isso, buscamos no texto analisar as influências da produção do MREF no campo acadêmico e nas biografias-identidades dos professores, ao atuar como um "outro" que criou dissonâncias, desestabilização, rupturas, enfim, como configurador de um impacto na área. Movimento que, apesar de seu "caráter legislador", criou a necessidade de pensar a EF articulada com um projeto mais amplo de escolarização, aspecto no qual reside a sua potência.

Quer dizer, se, por um lado, a crítica aqui operada deve ser tomada na direção da análise de um processo que gerou consequências para a área, cujo olhar em retrospectiva nos alerta para um constante repensar do próprio processo de produção teórica no campo, (mormente, naquilo que concerne ao reconhecimento das identidades, saberes e práticas daqueles que pisam o "chão da escola"); por outro lado, de maneira ambígua, não podemos ignorar neste impacto o impulso motivacional para o alcance de novas fronteiras de "autorrealização".

\section{REFERÊNCIAS}

BAUMAN, Zygmunt. Modernidade e ambivalência. Rio de Janeiro: Jorge Zahar, 1999.

BAUMAN, Zygmunt. Legisladores e intérpretes. Rio de Janeiro: Zahar, 2010.

BRACHT, Valter; GONZÁLEZ, Fernando Jaime. Educação Física escolar. In: GONZÁLEZ, Fernando Jaime.; FENSTERSEIFER, Paulo Evaldo. (Org.). Dicionário crítico de educação física. ljuí: Ed. Unijuí, 2005. p. 150-157.

CAPARROZ, Francisco Eduardo. Entre a Educação Física na escola e a Educação Física da escola. Vitória: CEFD/UFES, 1997.

DALBOSCO, Claudio Almir. Reificação, reconhecimento e educação. Rev. Bras. Educ. v. 16, n. 46, p. 33-51, abr. 2011. 
DEVÍS-DEVIIS, José; SPARKES, Andrew. La crisis de identidad de un estudiante universitario de educación física: un estudio biográfico. In: DEVÍS DEVÍS, José (Coord.). La educación física, el deporte y la salud en el siglo xxi. Alcoy: Editorial Marfil. 2001. p. 87-99.

FLICK, Uwe. Uma introdução à pesquisa qualitativa. Porto Alegre: Bookman, 2004.

FLICKINGER, Hans-Georg. Autonomia e reconhecimento: dois conceitos-chave na formação.

Educação, v. 34, n. 1, p. 7-12. jan./abr. 2011.

GONZÁLEZ , Fernando Jaime; FENSTERSEIFER, Paulo Evaldo. Entre o "não mais" e o "ainda não": pensando saídas do não-lugar da EF escolar I. Cadernos de formação RBCE, v. 1, n. 1, p. 9-24, 2009.

HONNETH, Axel. Reificación: un estudio en la teoría del reconocimiento. Buenos Aires: Kaatz, 2007.

HONNETH, Axel. Luta por reconhecimento: a gramática moral dos conflitos sociais. 2. ed. São Paulo: Ed. 34, 2009.

MACHADO, Thiago da Silva et al. As práticas de desinvestimento pedagógico na Educação Física escolar. Movimento, v. 16, n. 2, p. 129-148, abr./jun. 2010.

MACHADO, Thiago da Silva et al. Sobre o impacto do movimento renovador da educação física nas identidades docentes. 2012. 190 f. Dissertação (Mestrado em Educação Física) - Programa de Pós-Graduação em Educação Física, Universidade Federal do Espírito Santo, Vitória, 2012.

MATTOS, Patrícia. Axel Honneth: formas de desrespeito social. Mente, Cérebro e Filosofia, São Paulo, n. 8, p. 58-67, 2008.

MEAD, George Herbert. Mind, self and society: from the standpoint of a social behaviorist. 18 . ed. Chicago: Ed. Charles W. Morris, 1972. Em castelhano: Espíritu, persona y sociedad: desde el punto de vista Del conductismo social. 3. ed. Traducción de Florial Mazia. Buenos Aires: Paidós, 1972.

REZER, Ricardo. Relações entre o conhecimento e prática pedagógica no campo da educação física: pontos de vista... Motrivivência, v.19, n. 28, p. 38-62, 2007.

TABORDA DE OLIVEIRA, Marcos Aurélio. Para uma crítica da historiografia: as relações entre a ditadura militar e a Educação Física brasileira e a negação da experiência escolar do professor de Educação Física. In: FERREIRA NETO, Amarílio. (Org.). Pesquisa histórica na Educação Física. Vitória: Proteoria, 2001. v. 6, p. 5-48.

TAVARES DE FREITAS, Lorena Rodrigues. A aprendizagem cognitiva e moral em Axel Honneth e Michel Foucault e sua importância na compreensão do fracasso escolar das escolas públicas brasileiras. In: SEMINÁRIO NACIONAL SOCIOLOGIA \& POLÍTICA, 2., 2010. Curitiba. Anais..... Tendências e Desafios Contemporâneos. Curitiba: UFPR, 2010. Disponível em: http://www. humanas.ufpr.br/portal/seminariosociologiapolitica/2010-2/. Acesso em: 10 fev. 2014.

WINCH, Paula Gaida. Formação da identidade profissional de orientadores de estágio curricular pré-profissional: marcas de um possível coletivo. 2009. 290 f. Dissertação (Mestrado em Educação) - Programa de Pós-Graduação em Educação, Universidade Federal de Santa Maria, Santa Maria - RS, 2009.

Apoio:

O presente trabalho contou com apoio financeiro da Capes (bolsa de mestrado) e do CNPq (recursos por meio do Edital universal 2011). 